\title{
KOMPARASI METODE SIMPLE ADDITIVE WEIGHTIN (SAW) DAN METODE WEIGHTED PRODUCT (WP) DALAM MENENTUKAN KARYAWAN TERBAIK (STUDI KASUS: PT. MATRIXNET GLOBAL INDONESIA)
}

\author{
Nardiono \\ Teknik Informatika Universitas Pamulang \\ Email: nardie_on@yahoo.com
}

\begin{abstract}
ABSTRAK
Karyawan adalah tenaga kerja yang melakukan pekerjaan dan memberikan hasil kerjanya kepada pengusaha. Pemilihan karyawan terbaik merupakan kegiatan dalam perusahaan guna untuk memberi motivasi dan penghargaan agar karyawan bekerja lebih baik dan produktif. Salah satu sistem yang dapat digunakan dalam menentukan karyawan terbaik adalah dengan menggunakan sistem pendukung keputusan. Sistem pendukung keputusan adalah sistem yang digunakan untuk mendukung dan membantu pihak manajemen dalam melakukan pengambilan keputusan pada kondisi semi terstruktur dan tidak terstruktur. Sistem pendukung keputusan ini menggunakan metode SAW ( Simple Additive Weighting) dan metode WP (Weighted Product). Kedua metode ini bertujuan memilih alternative karyawan terbaik dari beberapa alternatife karyawan berdasarkan kriteria-kriteria ( kedisiplinan, sikap, kerjasama tim, prestasi, ketelatenan, penampilan ) yang telah ditentukan. Proses perhitungan dilakukan dengan mencari nilai bobot pada setiap alternative pada setiap kriteria. Karyawan yang terpilih yaitu yang memiliki nilai terbesar sebagai alternative terbaik. Dari hasil perhitungan metode SAW ( Simple Additive Weighting) dan WP (Weighted Product ), di dapatkan hasil perbandingan kedua metode. Metode SAW yang mendapatkan hasil lebih baik dibandingkan dengan metode WP, karena mendapat hasil yang lebih besar, tepat dan akurat.
\end{abstract}

Kata Kunci: Pemilihan Karyawan Terbaik, Sistem Pendukung Keputusan, Metode Weighted Product (WP), Metode Simple Additive Weighting (SAW).

\section{PENDAHULUAN}

Karyawan adalah tenaga kerja yang melakukan pekerjaan dan memberikan hasil kerjanya kepada pengusaha yang mengerjakan dimana hasil karyanya itu sesuai dengan profesi atau pekerjaan atas dasar keahlian sebagai mata pencariannya (Manullang, Manajemen Sumber Daya Manusia, 2002). Kedudukan karyawan dalam sebuah perusahaan sangatlah penting, oleh karena itu pengelolaan cukup penting karena akan mempengaruhi banyak aspek penentu keberhasilan kinerja perusahaan. Karyawan tentu erat kaitannya dengan kinerja, oleh karenanya, proses penilaian kinerja karyawan dirasa perlu dilakukan dalam suatu perusahaan, terutama dalam penentuan karyawan terbaik guna memberi motivasi dan penghargaan. Setiap perusahaan tentu memiliki cara yang berbedabeda dalam menentukan karyawan terbaiknya, tergantung pada kebijakan manajemen perusahaan.

PT. Matrixnet Global Indonesia adalah perusahaan yang bergerak dibidang usaha layanan jasa internet untuk masyarakat Indonesia. Perusahaan tersebut berdiri sejak 18 januari 2011. Seperti pada perusahaan jasa pada umumnya, karyawan akan berinteraksi langsung dengan pelanggan, sehingga keterampilan akan kinerja karyawan sangatlah penting demi pelayanan terbaik terhadap pelanggan yang akan berimbas terhadap kelangsungan perusahaan. Untuk menunjang hal tersebut, PT.Matrixnet Global Indonesia melakukan pemilihan karyawan terbaik terhadap para karyawannya. Adapun sistem yang berjalan saat ini dalam menentukan karyawan terbaik pada PT.Matrixnet Global Indonesia dinilai sudah cukup baik, yaitu setiap karyawan akan menilai kinerja karyawan lainnya, cara ini disebut sudah cukup baik karena karayawan akan melihat langsung kinerja rekan karyawan lainnya dibandingkan dengan ditunjuknya seseorang yang ditugaskan karena seseorang yang ditunjuk tersebut tidak dapat melihat kinerja karyawan yang menjadi kandidat karyawan terbaik setiap saat. Akan tetapi dalam proses pengolahan Pihak manajemen menemui kendala karena belum adanya metode yang dapat membantu pihak manajemen dalam pengambilan keputusan dalam proses pemilihan karyawan terbaik. Selain itu, pihak perusahaan juga sulit 
dalam mengimplementasikan kebijakan yaitu tidak semua kriteria memiliki tingkat kepentingan yang sama, dengan kata lain setiap kriteria memiliki tingkat kepentingan yang berbeda-beda.

Ada beberapa metode yang dapat digunakan dalam membantu proses penyeleksian atau pemilihan karyawan terbaik, metode yang dipakai adalah metode Weighted Product dan metode Simple Additive Weighting. Kedua Metode ini adalah metode penyelesaian pada masalah MADM (Multi Attribute Decision Making).

\section{METODE PENELITIAN}

\subsection{Metode Pengumpulan Data}

Metode pengumpulan data meliputi adalah sebagai berikut:

a. Tinjauan langsung (Observasi)

Merupakan Teknik pengumpulan data yang dilakukan melalui suatu pengamatan secara langsung kegiatan yang dilakukan pada tempat penelitian guna memperoleh gambaran yang relevan dengan masalahmasalah dan tujuan penelitian dengan disertai pencatatan-pencatatan terhadap keadaan atau prilaku objek sasaran di PT.Matrixnet Global Indonesia.

b. Wawancara

Merupakan sebuah proses memperoleh keterangan dengan Teknik tanya jawab sambil bertatap muka langsung dengan responden atau orang yang diwawancara, dengan atau tanpa menggunakan pedoman wawancara. Wawancara ini dilakukan guna mendapatkan informasi sebagai pendukung observasi. Wawancara dilakukan untuk menagkap informasi lebih lengkap mengenai permasalahan yang diteliti yang tidak terjaring melalui observasi.

c. Studi Pustaka

Dalam penelitian ini tidak terlepas dari beberapa sumber yang digunakan seperti halnya jurnal-jurnal, buku, serta karya ilmiah lainnya yang memberikan informasi guna untuk menyelesaikan penelitian.

\subsection{Metode Analisa Data}

Setelah data terkumpul, tahapan selanjutnya pada penelitian ini adalah tahapan pengolahan serta analisa data. Analisa data pada penelitian ini menggunakan 2 metode sebagai komparasi, adalah sebagai berikut: a. Pengembangan sistem SAW (Simple Additive Weighting)

Pengembangan suatu sistem pendukung keputusan terkait juga dengan struktur permasalahan tak terstruktur, semi terstruktur, ataupun terstruktur. Dibawah ini merupakan tahap pengembangan sistem penunjang keputusan (Brigida Arie, 2015). Tahap pengembangan sistem pendukung keputusan :

1) Tahap perencanaan (Planning)

Merumuskan kerangka dan ruang lingkup sistem, persyaratan unjuk kerja, memilih konsep-konsep dan menganalisis model pembuatan keputusan.

2) Tahap penelitian (Research) Berhubungan dengan pencarian data serta sumber daya yang tersedia.

3) Tahap analisis dan perancangan konsep (Analysis)

Penentuan teknik pendekatan yang akan dilakukan serta sumber daya yang dibutuhkan.

4) Tahap perancangan (Design) Melakukan perancangan tiga subsistem utama yaitu database, model, dialog.

5) Tahap konstruksi (Construction)

Merupakan kelanjutan dari perancangan dimana ketiga subsistem yang telah dirancang digabungkan menjadi suatu SPK.

6) Tahap implementasi (Implementation) Menerapkan SPK yang dibangun, pada tahap ini dilakukan pengujian, evaluasi, penampilan, orientasi, pelatihan dan penyebaran.

7) Tahap pemeliharaan (Maintenance)

Tahapan yang dilakukan terus menerus untuk mempertahankan keandalan sistem.

8) Tahap adaptasi (Adaptation)

Melakukan pengulangan terhadap tahapan diatas sebagai tanggapan terhadap perubahan kebutuhan pemakai.

b. Pengembangan sistem WP (Weighted Product)

Metode pengembangan sistem menggunakan tahap-tahap pengembangan sistem pakar karena menggabungkan pengetahuan manusia (pakar) dan teknologi komputer agar dapat menyelesaikan masalah yang biasanya 
diselesaikan oleh para pakar atau ahli (Kusumadewi, Artificial Intelligence (Teknik dan Aplikasinya), Graha Ilmu, Yogyakarta., 2003). Tahap pengembangan sistem pendukung keputusan:

1) Mengidentifikasikan masalah dan keutuhan. Mengkaji situasi dan memutuskan dengan pasti tentang masalah yang akan dikomputerisasi dan apakah dengan sistem pakar bisa lebih membantu atau tidak

2) Mempertimbangkan alternatif. Dalam hal ini ada dua alternatif yaitu menggunakan sistem pakar atau komputer tradisional

3) Menghitung pengambilan investasi. Termasuk antaranya: biaya pembuatan sistem pakar, biaya pemeliharaan dan biaya pelatihan.

4) Memilih alat pengembangan Bisa digunakan pembuat sistem

5) Pakar (seperti SHELL) atau dirancang dengan bahaspemograman sendiri (misalnya dengan menggunakan PROLOG)

6) Menguji dan mencari kesalahan sistem

7) Memelihara sistem. Dalam hal ini harus dilakukan: memperbaharui pengetahuan, mengganti pengetahuan yang sudah ketinggalan dan meluweskan sistem agar bisa lebih baik lagi dalam menyelesaikan masalah

\section{HASIL DAN PEMBAHASAN}

\subsection{Uraian Prosedur Sistem Berjalan}

Berikut penulis paparkan system berjalan gambar rich picture.

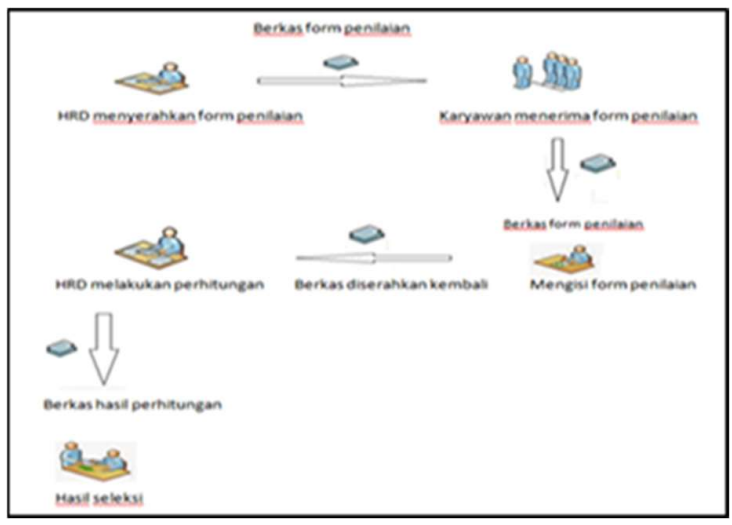

Gambar 1. Rich Picture Sistem Berjalan

\subsection{Perancangan Sistem Usulan Use Case Diagram Sistem Usulan}

Berikut ini adalah system yang sedang berjalan yang akan dibuta terdapat pada gambar berikut:

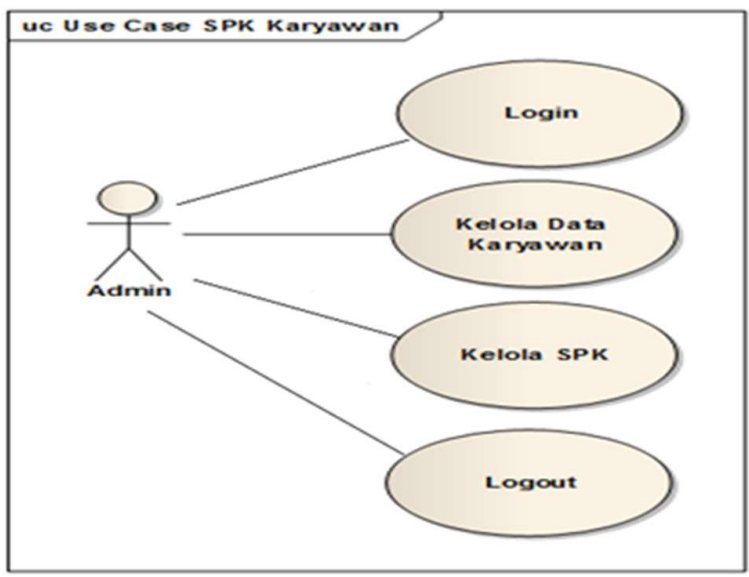

Gambar 2. Use Case Diagram SPK Karyawan Terbaik

\subsection{Perancangan Basis Data Entity Relationship Diagram (ERD)}

Dalam hal ini akan digunakan Entity Relationship Diagram (ERD) untuk merancang basis data. ERD yang merupakan hasil analisis sebagai berikut:

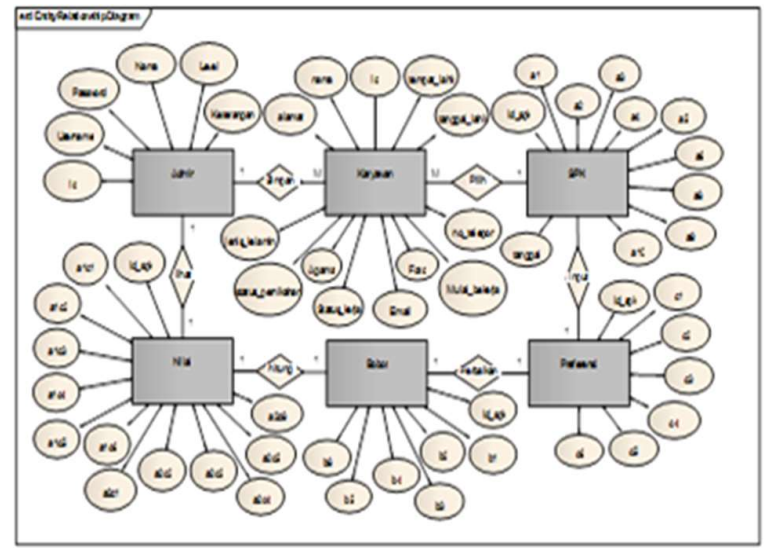

Gambar 3. Entity Relationship Diagram SPK Karyawan Terbaik

\section{Logical Record Setructure (LRS)}

Setelah ditransformasikan ERD ke LRS, makabentuk Logical Record Structure (LRS) yang sudah terbentuk seperti pada gambar dibawah ini: 


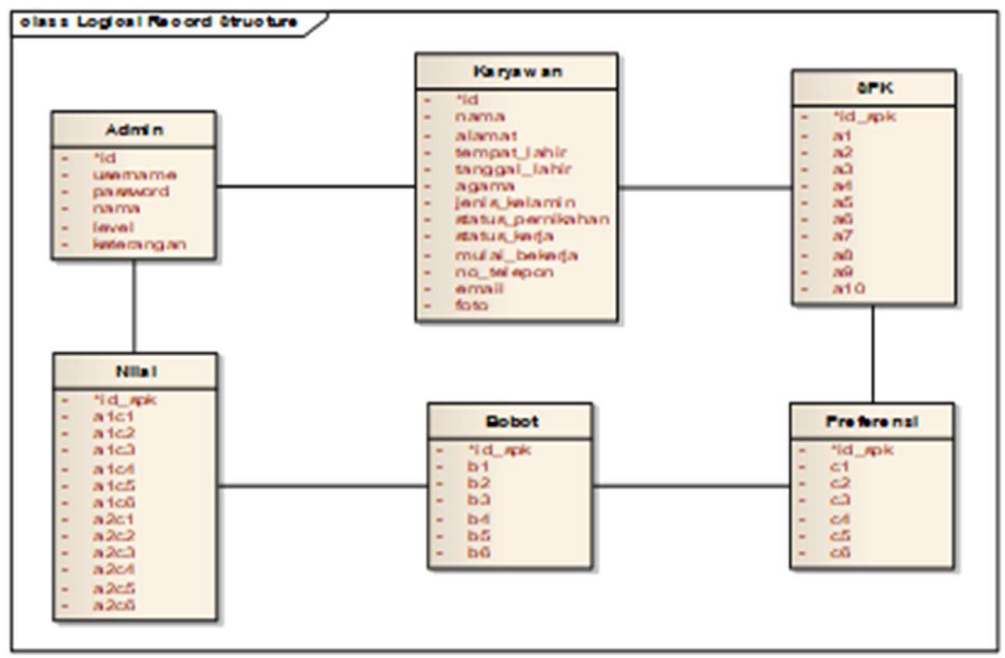

Gambar 4 Logical Record Structure SPK Karyawan Terbaik

\section{Transformasi ERD ke LRS}

Dibawah ini adalah diagram langkah atau proses transformasi dari diagram ERD (Entity
Relationship Diagram) ke LRS (Logical Record Structure).

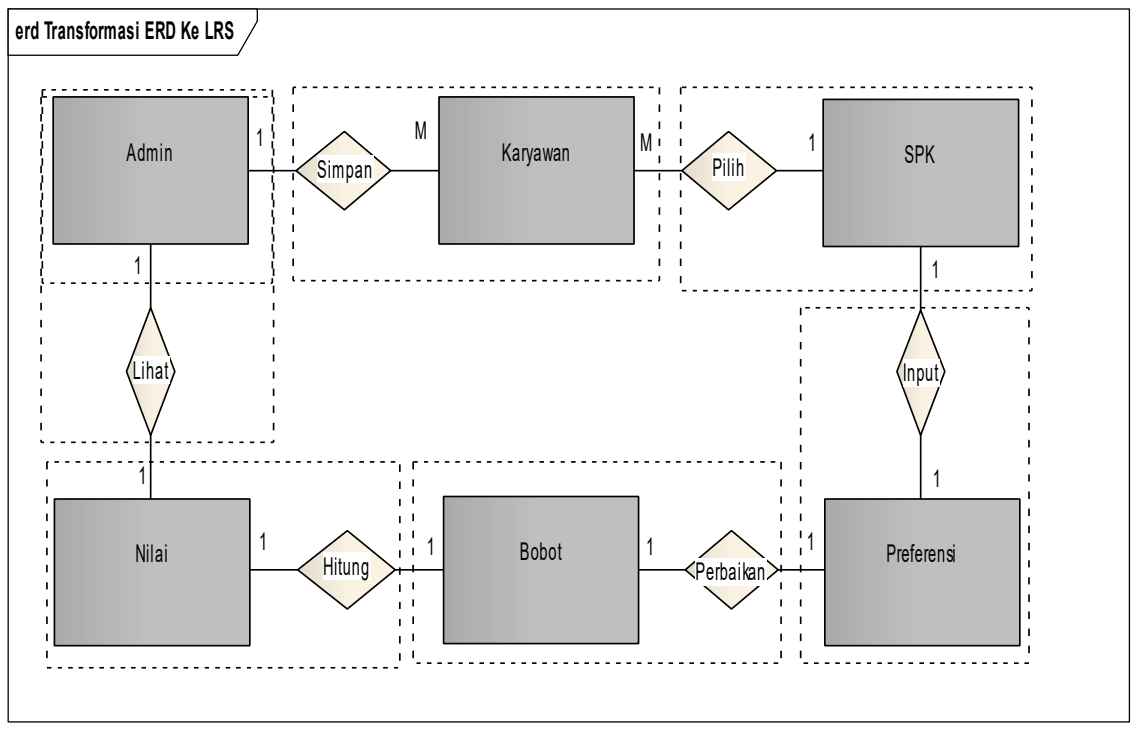

Gambar 5. Transformasi ERD ke LRS

3.4. Penerapan Metode Simple Additive Weighting (SAW) dan Weighted Product (WP)

Kriteria dan Bobot

Dalam metode Simple Additive Weighting (SAW) dan Weighted Product (WP) terdapat kriteria yang dibutuhkan untuk menentukan siapa yang akan terpilih sebagai karyawan terbaik. Adapun kriterianya adalah sebagai berikut :
Tabel 3. 1 Daftar Kriteria

\begin{tabular}{|c|c|}
\hline Kriteria & Keterangan \\
\hline C1 & Disinln \\
\hline C2 & Attitude \\
\hline C3 & Teamwork \\
\hline C4 & Prestasi \\
\hline C5 & Retelatenan \\
\hline C6 & Penampilan \\
\hline
\end{tabular}


Adapun bilangan bobot atau tingkat kepentingan yang akan diberikan pada masingmasing kriteria dinilai dengan 1 sampai 5, yaitu :

Tabel 3. 2 Tingkat Kepentingan (bobot)

\begin{tabular}{|c|c|}
\hline Angka & Ke terangan Bobot \\
\hline 1 & Sangat Rendah (SR) \\
\hline 2 & Rendah (R) \\
\hline 3 & Cukup (C) \\
\hline 4 & Tinggi (T) \\
\hline 5 & Sangat Tinggi (ST) \\
\hline
\end{tabular}

Untuk rating kecocokan setiap alternative pada setiap kriteria, juga dinilai dengan 1 sampai 5, yaitu:

Tabel 3. 3 Rating Kecocokan

\begin{tabular}{|l|l|}
\hline Angka & Rating Ke cocokan \\
\hline 1 & Sangat Buruk (SB) \\
\hline 2 & Buruk (BR) \\
\hline 3 & Cukup (C) \\
\hline 4 & Baik (B) \\
\hline 5 & Sangat Baik (SB) \\
\hline
\end{tabular}

Perhitungan Penilaian Karyawan Berprestasi dengan Metode Simple Additive Weighting (SAW)

a. Hitung normalisasi dari setiap alternatife dengan rumus sebagai berikut;

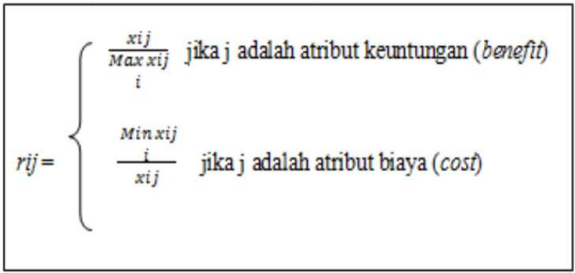

Keterangan :

rij = nilai rating kinerja ternormalisasi $\mathrm{xij}=$ nilai atribut yang dimiliki setiap kriteria

Max xij = nilai terbesar dari setiap kriteria Min $x i j=$ nilai terkecil dari setiap kriteria Benefit $=$ jika nilai terbesar adalah terbaik Cost $=$ jika nilai terkecil adalah terbaik

Maka didapat matriks r:

\begin{tabular}{|c|c|c|c|c|c|}
\hline 0,8 &, 8 & 0,8 & 0,8 & 0,6 & $0,8)$ \\
\hline 0,8 & 0,8 & 1 & 0,6 & 0,8 & 0,8 \\
\hline 1 & 1 & 0,8 & 0,8 & 1 & 0,6 \\
\hline 0,8 & 0,8 & 0,8 & 0,6 & 0,8 & 1 \\
\hline 0,8 & 1 & 0,6 & 0,6 & 0,8 & 0,8 \\
\hline 0,6 & 0,8 & 0,8 & 0,8 & 0,8 & 1 \\
\hline 1 & 1 & 0,6 & 0,8 & 0,8 & 0,8 \\
\hline 0,8 & 1 & 0,6 & 0,8 & 1 & 0,8 \\
\hline 1 & 0,75 & 1 & 1 & 0,75 & 1 \\
\hline 1 & 0,8 & 0,8 & 0,6 & 0,8 & 0,8 \\
\hline 1 & 1 & 0,75 & 0,75 & 1 & 1 \\
\hline 1 & 0,6 & 0,8 & 0,6 & 0,8 & 0,8 \\
\hline 1 & 0,8 & 1 & 1 & 1 & 0,8 \\
\hline 0,8 & 0,8 & 0,8 & 1 & 0,8 & 1 \\
\hline 0,6 & 0,8 & 1 & 0,6 & 0,8 & 0,8 \\
\hline 0,8 & 0,6 & 0,6 & 1 & 1 & 0,8 \\
\hline 1 & 1 & 1 & 0,8 & 0,6 & 0,6 \\
\hline 0,8 & 1 & 0,8 & 1 & 1 & 0,8 \\
\hline 0,8 & 1 & 0,8 & 0,8 & 0,8 & 0,8 \\
\hline 0,8 & 0,8 & 0,8 & 1 & 0,8 & 0,8 \\
\hline 0,6 & 0,8 & 0,6 & 0,6 & 0,8 & 1 \\
\hline 0,75 & $5 \quad 1$ & 1 & 0,75 & 1 & 1 \\
\hline 0,8 & 0,8 & 0,8 & 0,8 & 1 & 0,8 \\
\hline 0,8 & 0,6 & 0,6 & 1 & 0,8 & 1 \\
\hline 1 & 0,75 & 1 & 0,75 & 1 & 1 \\
\hline
\end{tabular}

Melakukan proses perangkingan dengan menggunakan rumus sebagai berikut:

$$
V i=\sum_{j=1}^{n} w j r i j
$$

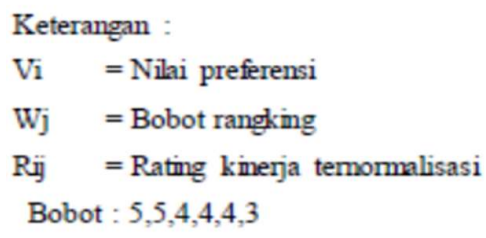

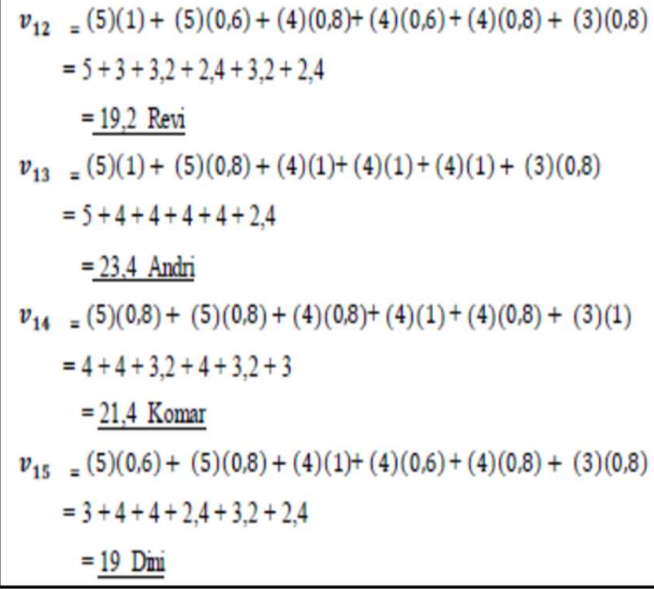

Nilai terbesar terdapat pada alternatife V13 terpilih menjadi prioritas utama, dengan kata lain Andri terpilih dan berhak mendapat reward sebagai pemilihan karyawan terbaik pada PT. Matrixnet Global Indoensia. 
Perhitungan Penilaian Karyawan Berprestasi dengan Metode Weighted Product (WP)

Tahapan pertama adalah dilakukan perbaikan bobot terlebih dahulu. Bobot awal $\mathrm{W}=(5,5,4,4,4,3)$, akan diperbaiki sehingga total bobot $\Sigma \mathrm{wj}=1$, dengan cara:

$$
\begin{aligned}
& \mathrm{w} 1=\frac{5}{5+5+4+4+4+3}=\frac{5}{25}=0,2 \\
& \mathrm{w} 2=\frac{5}{5+5+4+4+4+3}=\frac{5}{25}=0,2 \\
& \mathrm{w} 3=\frac{4}{5+5+4+4+4+3}=\frac{4}{25}=0,16 \\
& \mathrm{w} 4=\frac{4}{5+5+4+4+4+3}=\frac{4}{25}=0,16 \\
& \mathrm{w} 5=\frac{4}{5+5+4+4+4+3}=\frac{4}{25}=0,16 \\
& \mathrm{w} 6=\frac{3}{5+5+4+4+4+3}=\frac{3}{25}=0,12
\end{aligned}
$$

Sehingga $\Sigma \mathrm{w}=$

$(0,2+0,2+0,16+0,16+0,16+0,12)=1$.

Tahapan kedua adalah perhitungan vektor $S$ dengan menggunakan persamaan berikut:

$$
S_{i}=\prod_{j=1}^{n} x_{i j}{ }^{w_{j}} \quad \begin{aligned}
\text { dengan } i & =1,2,3, \ldots, m . \\
j & =1,2,3, \ldots, n .
\end{aligned}
$$

\section{Implementasi Sistem}

a. Form Halaman utama
Di mana $\Sigma w j=1$. Wj adalah pangkat bernilai positif untuk atribut keuntungan, dan bernilai negatif untuk atribut biaya namun pada kasus di PT. Matrixnet Global Indonesiasemua atributnya keuntungan sehingga pangkat dari kesemuanya bernilai positif. Sehingga $\Sigma \mathbf{s}=$ 98,72483 dan akan digunakan pada proses pencarian nilai pada vektor $\mathrm{V}$.

Tahapan ketiga atau tahapan terakhir adalah mencari nilai dari vektor $\mathrm{V}$. Nilai vektor $\mathrm{V}$ yang digunakan untuk perangkingan dapat dihitung dengan persamaan berikut:

$$
\begin{aligned}
& \mathrm{v}_{\mathrm{i}}=\frac{\prod_{\mathrm{j}=1}^{\mathrm{n}} \mathrm{x}_{\mathrm{ij}} \mathrm{w}_{\mathrm{i}}}{\prod_{\mathrm{j}=1}^{\mathrm{n}}\left(\mathrm{x}_{\mathrm{j}}^{*}\right)^{\mathrm{w}_{\mathrm{i}}}} \\
& \mathrm{v}_{12}=\frac{3,7710}{98,72483}=0,03819 \\
& \mathrm{v}_{13}=\frac{4,6554}{98,72483}=0,04715 \\
& \mathrm{v}_{14}=\frac{4,2579}{98,72483}=0,04312 \\
& \mathrm{v}_{15}=\frac{3,7375}{98,72483}=0,03786
\end{aligned}
$$

Dari perhitungan diatas dapat dilihat nilai terbesar ada pada V13, sehingga alternatif A13 adalah alternatif yang terpilih sebagai alternatif terbaik. Dengan kata lain, Andri akan terpilih sebagai karyawan terbaik. 


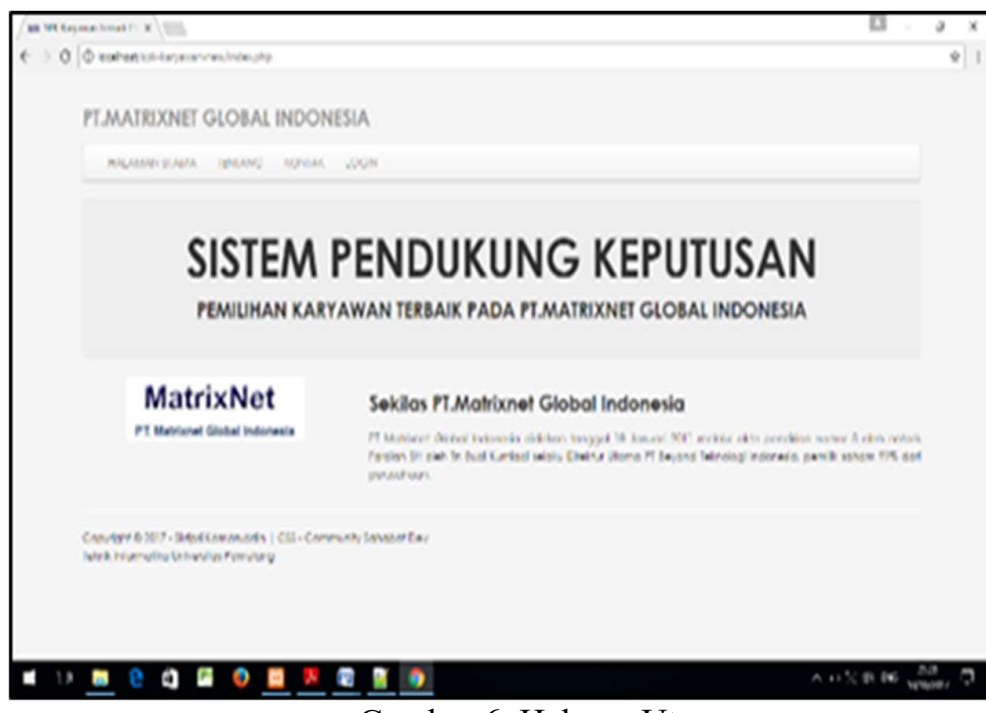

Gambar 6. Halamn Utama

b. Form Sistem Pendukung Keputusan

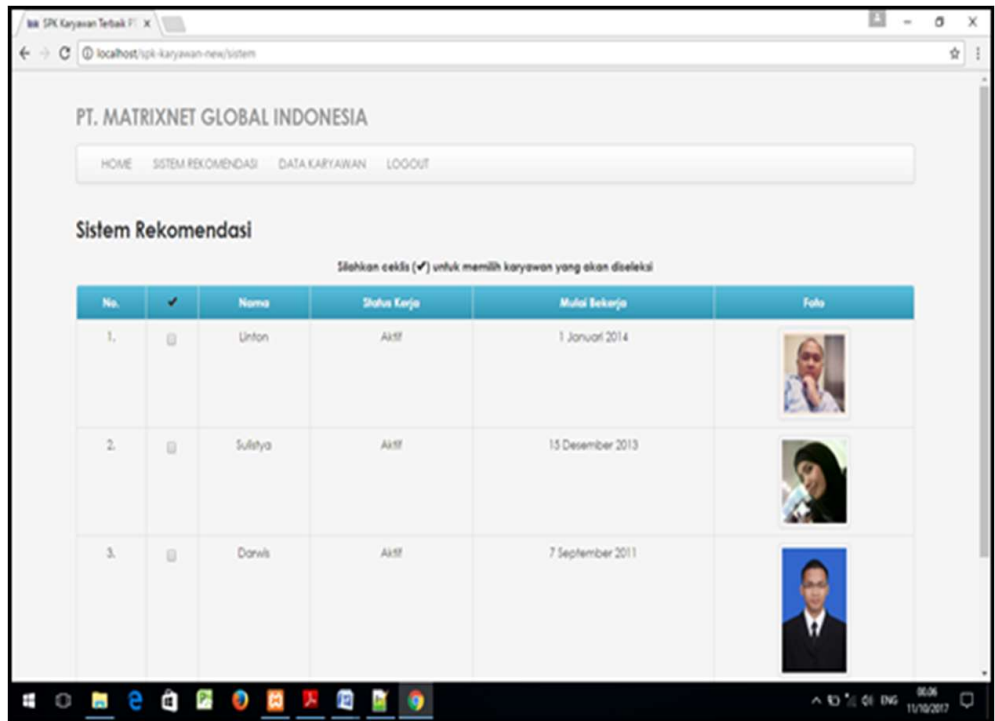

Gambar 7. Form Sistem Pendukung Keputusan

c. Form Menentukan Bobot Kriteria 


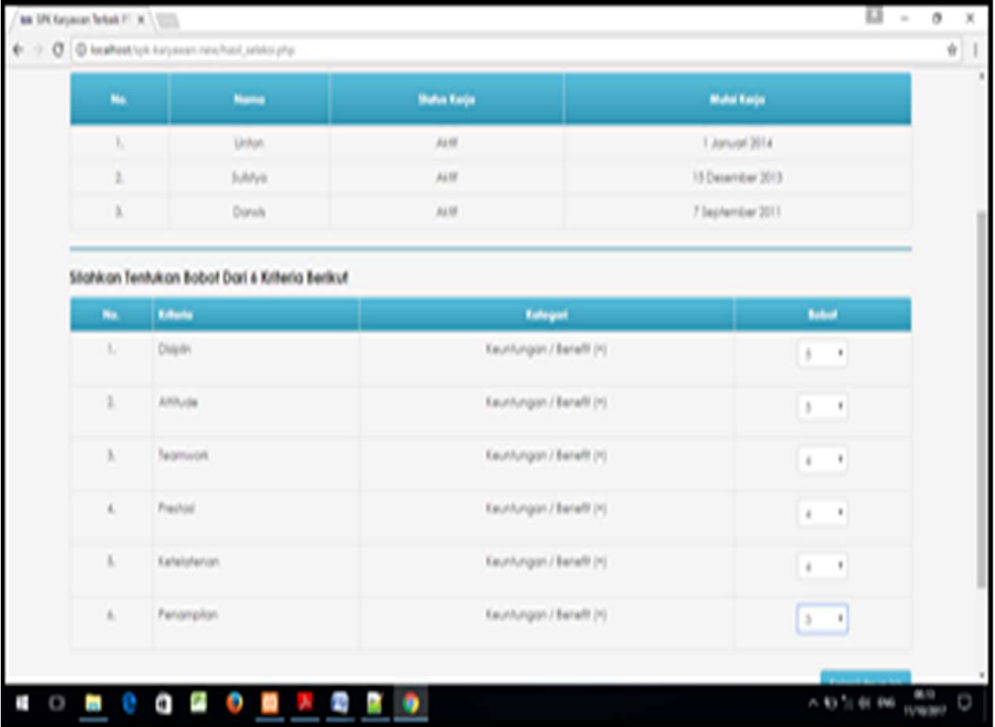

Gambar 8. Form Menentukan Bobot Karyawan

d. Form Hasil Penilaian

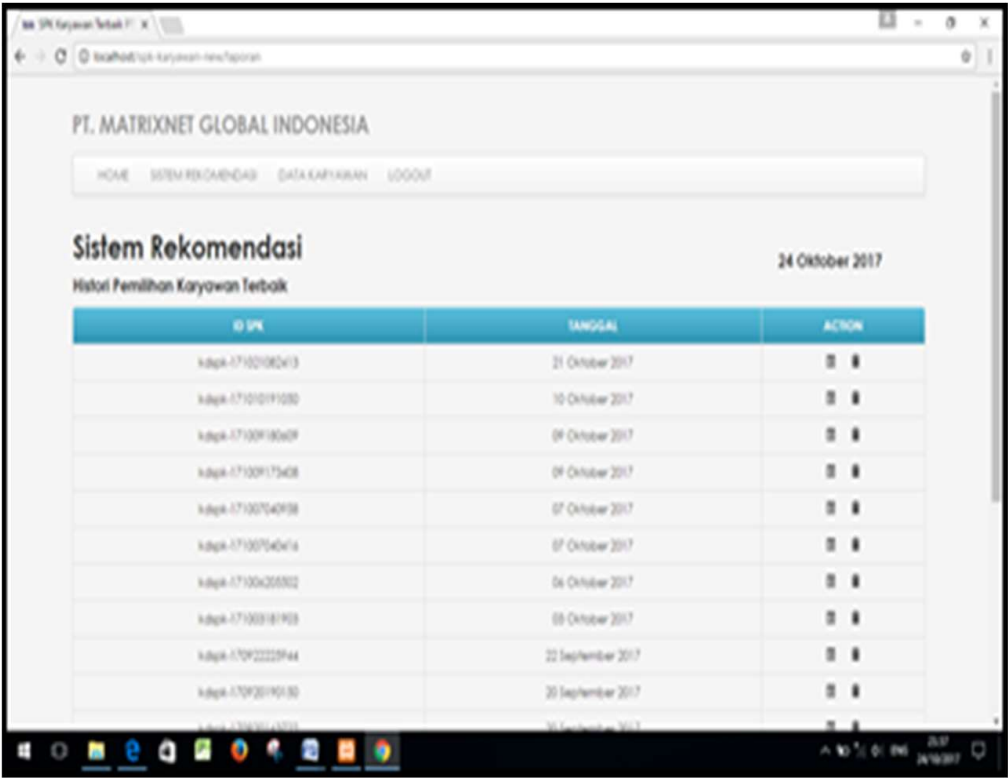

Gambar 9. Form Hasil Penilaian

\section{KESIMPULAN}

Dalam penelitian ini telah diuraikan bagaimana perancangan dan penerapan metode SAW dan WP dalam membuat sistem pendukung keputusan pemilihan karyawan. Maka dapat penulis simpulkan:

a. Setelah dilakukan perhitungan dengan menggunakan metode SAW dan WP dalam pemilihan karyawan terbaik dan membandingkan mana yang lebih baik antara kedua metode tersebut, maka didapat hasil perbandingan bahwa metode SAW lebih baik dibandingkan dengan metode WP,karena metode SAW lebih tepat dan akurat dalam melakukan perhitungan dibanding metode WP.

b. Untuk penerapan pemilihan karyawan terbaik dibuat aplikasi berbasis web dengan perhitungan yang diawali pemberian bobot pada tiap-tiap kriteria yang sudah ditentukan perusa5. haan diproses dengan menggunakan metode 
SAW dan WP untuk mendapatkan hasil perbandingan.

\section{DAFTAR PUSTAKA}

[1] Jasril, Haerani, E., \& Afrianty, I. (2011). Sistem Pendukung Keputusan (SPK) Pemilihan Karyawan Terbaik Menggunakan Metode Fuzzy AHP (F-AHP). Seminar Nasional Aplikasi Teknologi Informasi ISSN: 1907-5022, 36-43

[2] Kustiyahningsih, Y., \& Anamisa, D. R. (2011). Pemrograman Basis Data Berbasis Web Menggunakan PHP \& MySQL. Yogyakarta: GRAHA ILMU

[3] Kusumadewi. (2006). Pembahasan SPK. Jakarta: Logam.

[4] Kusumadewi, S., Hartati, S., Harjoko, A., \& Wardoyo, R. (2006). Fuzzy Multi-Attribute Decission Making (FUZZY MADM). Yogyakarta: GRAHA ILMU

[5] Manullang. (2002). Manajemen Sumber Daya Manusia. Jakarta: Ghalia Indonesia

[6] Rachmawati, Y. D. (2010). Sistem Pendukung Keputusan Penentuan Karyawan Terbaik Menggunakan Metode SAW (Simple Additive Weighting) STUDI KASUS: PT.PERTAMINA RU II DUMAI). sistem Informasi, Politeknik Celtex riau

[7] Rijayana， I., \& Okirindho, L. (2012). Sistem Pendukung Keputusan Pemilihan Karyawan Berprestasi Berdasarkan Kinerja Menggunakan Metode Analitic Hierarcy Process. Seminar Nasional Informatika , ISSN: 1979-2328, 48-53 